\title{
Applications of the Polymerase Chain Reaction in Environmental Microbiology
}

\author{
Asim K. Bej ${ }^{1}$ and Meena H. Mahbubani2 \\ Departments of ${ }^{1}$ Biology and ${ }^{2}$ Microbiology, University of Alabama at \\ Birmingham, Alabama 35294
}

\begin{abstract}
$\mathbf{T}_{\mathrm{n}}$ he application of the polymerase chain reaction ${ }^{(1-5)}$ (PCR) to explore various areas of environmental microbiology has the potential to solve many difficult and unanswered questions about microbial activities in the environment at the physiological and molecular levels. This review describes the use of PCR for the detection of specific microbes in environmental samples and discusses how PCR may be used to answer future questions in molecular microbial ecology. The first two sections of the review will discuss preparation of nucleic acids from environmental microorganisms and PCR methodology specific to environmental microbiology. Subsequent sections present information on applying these methods to environmental problems such as: detection of genetically engineered microbes, detection of indigenous microorganisms in the environment and indicator microorganisms in water, detection of waterborne microbial pathogens and viable but nonculturable microorganisms, and environmental monitoring with multiplex PCR.
\end{abstract}

\section{PURIFICATION OF NUCLEIC ACIDS FROM ENVIRONMENTAL MICROORGANISMS FOR PCR AMPLIFICATION}

Extraction and extensive purification of nucleic acids from environmental microorganisms is necessary for successful PCR amplification. Some of the general environmental contaminants that can inhibit the PCR reaction are the presence of humic materials, clay, and organics. For example the addition of as little as $0.001 \mu \mathrm{g}$ of montomorillite humic material in the PCR reaction inhibits the amplification process (A. Bej, unpubl.).

\section{Purification of Nucleic Acids from Soil and Sediment}

Much effort has been devoted to developing convenient methods for removing humic materials from environmental samples to achieve successful PCR amplification of the target nucleic acids. Either direct lysis or isolation of bacterial cells followed by lysis can be used for extraction of DNA from microorganisms present in the environmental soil or sediment. ${ }^{(6)}$ Purification of the released DNA can be performed by applying a combination of the various standard purification methods such as phenol-chloroform extraction followed by ammonium acetate-ethanol precipitation, repeated polyvinylpolypyrrolidone (PVPP) treatment or dialysis, hydroxylapatite or affinity chromatography, and multiple $\mathrm{CsCl}-$ $\mathrm{EtBr}$ density gradient centrifugation. All of these methods produce positive PCR amplification from the environmental samples. Recently, Tsai and OIson $^{(7)}$ have described a direct extraction method using lysozyme followed by freeze-thaw disruption of the cells. The released DNAs were then purified by standard phenol-chloroform extraction and chromatography. In another study, bacterial cells were differentially separated from soil colloids on the basis of their buoyant densities. ${ }^{(8)}$ In this method, a modified sucrose gradient centrifugation protocol is used to separate most of the soil colloids from the bacterial cells in the sample for PCR amplification of the target DNA.

To isolate and purify RNA from environmental microorganisms, the samples can be treated with guanidinium hydrochloride, and phenolchloroform-isoamyl alcohol extraction followed by ethanol precipitation. ${ }^{(9)}$ Although significantly higher amounts of nucleic acids can be recovered by following the direct lysis method, the presence of eukaryotic DNA in the sample is a possibility.

\section{Purification of Nucleic Acids from Microorganisms in Water}

Nucleic acids for PCR amplification from microorganisms present in the aquatic environment can be isolated and purified more easily than those from soil and sediment. A simple method for isolating nucleic acids from aquatic samples has been demonstrated by Sommersville et al. ${ }^{(10)}$ and consists of collecting cells, followed by lysis and separation of plasmid DNA, chromosomal DNA, and RNA in a single filter cartridge. The dissolved and particulate DNA then can be conveniently purified for $P C R$ analysis. ${ }^{111,12)}$ In various other studies, the following procedures were found to be essential to yield sufficiently pure DNA for various molecular biological analyses and perhaps PCR analyses: $\mathrm{CsCl}-\mathrm{EtBr}$ density gradient centrifugation $^{(12)}$ for all environmental DNAs, multiple PVPP treatment for rRNA studies, ${ }^{(13)}$ and repeated phenol-chloroform extractions for total planktonic $\mathrm{DNA}^{(14,15)}$ or cyanobacterial DNA. ${ }^{(16)}$

Microbial cells can be collected on a filter, lysed by repeated freeze-thaw methods, and used for PCR amplification without removing the filter from the reaction tube. ${ }^{(17)}$ Alternatively, filtered cells can be lysed directly on the filter by lysozyme, and the released 
DNA can be purified by phenol-choroform extraction followed by ethanol precipitation to yield adequately purified DNA for PCR amplification and analysis. (18)

Although the methods described above can remove the majority of the environmental contaminants and are useful for various molecular biological studies, there is no standard protocol for removing all possible inhibitors that can be applied for all types of environmental samples.

\section{PCR METHODOLOGY FOR ENVIRONMENTAL APPLICATIONS}

Basically, PCR is the in vitro enzymatic amplification of a DNA fragment that is performed by using two flanking oligonucleotide primers at the two ends of the target DNA. ${ }^{(3)}$ This methodology has several advantages, as well as disadvantages, over conventional methodologies used in environmental microbiology. Some of the recent advancements in PCR technology that may be very useful in environmental applications and that we would like to discuss in some detail are: (1) "hot start," (2) removal of PCR carryover contaminants, and (3) thermostable DNA polymerase from various thermotolerent microorganisms, some of them with additional activities such as reverse transcriptase.

\section{Hot Start}

The specificity of oligonucleotide primers for the amplification of a specific target for detecting a specific microbial pathogen or a released genetically engineered microorganism (GEM) in the environment can be determined by testing varieties of $\mathrm{mi}$ croorganisms. However, because of the vast diversity of microorganisms in any environmental sample, it is possible that one may get nonspecific PCR amplification. (19) Thus, increased specificity is an important issue for environmental PCR. Methods such as increasing or decreasing $\mathrm{MgCl}_{2}$ concentrations in the PCR reaction, high $T_{m}$ value of the primers with an approximately $50 \%$ GC content, and a random base distribution minimum of 5-6 bases at the 3 'end of each of the primers can be used to remove nonspecific amplified DNA. Also effective is the "hot start" method. $(19,20)$ This method is based on the fact that nonspecific priming and subsequent production of unwanted amplified DNA bands generally result due to the retention of considerable enzymatic activity at temperatures below the optimum for DNA synthesis. Therefore, during the initial heating step of the PCR reaction, primers that anneal nonspecifically to a partially single-stranded template region can be extended and stabilized before the reaction reaches the $72^{\circ} \mathrm{C}$ temperature for extension of specifically annealed primers. If the DNA polymerase is activated only after the reaction has reached high $\left(>70^{\circ} \mathrm{C}\right)$ temperatures, nontarget amplification can be minimized by manual addition of an essential reagent, e.g., DNA polymerase, to the reaction tube at elevated temperatures. This approach improves specificity and minimizes the formation of "primer dimers."

\section{Removal of PCR Carryover Contamination}

Another potential problem is contamination of the PCR amplification reaction with products of a previous PCR reaction, i.e., product carryover, cross-contamination between samples, or contamination with exogenous nucleic acids from the laboratory environment, all of which can create false-positive results. Although some general precautions and good laboratory practice will reduce the possibility of such contamination problems, ${ }^{(21)}$ other simple and more effective preventive measures can be taken by exposing the reaction mixture to ultraviolet light, (22) treating the reaction mixture with multiple restriction enzymes or DNase I, followed by inactivation of these enzymes, or photochemical modification of the contaminating DNA with psoralen or isopsoralen. ${ }^{(23,24)}$

Another effective approach is to make contaminating PCR products susceptible to degradation by substituting dUTP for dTTP in every PCR reaction and treating the subsequent PCR reaction mix with uracil DNA glycosylase, ${ }^{(25)}$ which will selectively eliminate dU-containing DNA by cleaving the uracil. This enzyme is active for both double- and single-stranded DNAs containing abasic polynucleotide (dUTP), but does not react on RNA template.
Thus, when a PCR reaction is contaminated with RNA, this approach will not be useful and false amplification may result. Another problem with this approach is that the amplified DNA must be stored at high temperature $\left(72^{\circ} \mathrm{C}\right)$ until it is transferred to a freezer to prevent degradation of the newly amplified DNA product from any residual activity of the enzyme.

\section{Thermostable DNA Polymerase}

Native Taq DNA polymerase and recombinant AmpliTaq DNA polymerase of Thermus aquaticus are commonly used for DNA amplification by PCR. Recently, several other thermostable DNA polymerases have been introduced and these may have potential advantages for environmental PCR technology. The Stoffel fragment, a modified version of the Taq DNA polymerase in which 289 amino acids are deleted from the amino-terminal end of the enzyme, is approximately twofold more thermostable, exhibits optimal activity over a broader range of magnesium ion concentrations (2-10 $\mathrm{mm})$, and lacks any intrinsic $5^{\prime} \rightarrow 3^{\prime}$ exonuclease activity compared to the complete Taq DNA polymerase. As a result, when using the Stoffel fragment, the denaturation temperature can be raised several degrees ${ }^{(19)}$; this is useful for templates that are $\mathrm{G}+\mathrm{C}$-rich or that contain complex secondary structures. Many environmental microbes are identified by amplifying ribosomal RNA, which may have such complex secondary structure, as targets. In addition, when using the Stoffel fragment, the primer can be selected with higher annealing temperature for better specificity and the entire PCR reaction can be performed at an elevated temperature without losing much of the enzyme activity.

Another thermostable DNA polymerase isolated from Thermus thermophilus (Tth) has significant reverse transcriptase activity, especially in the presence of $\mathrm{MnCl}_{2} \cdot{ }^{(19)}$ Tth polymerase can be useful for detecting gene expression and viable but nonculturable microorganisms in the environmental samples by using mRNA-cDNA-PCR amplification in a single reaction.

Recently, several other thermostable DNA polymerases have been isolated and tested for their fidelity, 
stability at high temperatures, and exonuclease activities. (26-28) The fidelity of the DNA polymerase isolated from Thermococcus litoralis (Vent DNA polymerase) has been studied and compared with other DNA polymerases such as Taq, Klenow, T4, and T7 DNA polymerases by Eckert and Kunkel. (29) The advantage of using Vent DNA polymerase is that it has $3^{\prime} \rightarrow 5^{\prime}$ exonuclease activity, which increases the fidelity of the reaction about sixfold as compared to the Taq DNA polymerase. It is noteworthy to mention that Vent DNA polymerase has a base substitution error rate of $1 / 31,000$ in a reaction containing $1 \mathrm{mM}$ dNTPs, which is similar to that observed for the Klenow DNA polymerase. Interestingly, $T$. litoralis grows at a temperature of $98^{\circ} \mathrm{C}$ in thermal vents on the ocean floor, and Vent DNA polymerase, isolated from this organism, retains its activity for over $2 \mathrm{hr}$ at $100^{\circ} \mathrm{C}$, with a primer extension capacity of up to $13 \mathrm{~kb} \cdot{ }^{(30)}$

Recently, another thermostable DNA polymerase has been isolated from a thermophilic, anaerobic, marine archaebacterium, Pyrococcus furiosus ( $p f u$ ). The pfu DNA polymerase is a monomeric, $92-\mathrm{kD}$ protein with both $5^{\prime} \rightarrow 3^{\prime}$ and $3^{\prime} \rightarrow 5^{\prime}$ exonuclease activities. ${ }^{(31)}$ pfu has better thermostability at $95^{\circ} \mathrm{C}$ than some other thermostable DNA polymerases and has a 12-fold lower mutation frequency than Taq DNA polymerase.

Eckert and Kunkel(32) have shown in a comparison of the fidelities of the various thermostable DNA polymerases that Tth and the Thermus flavis Replinase are 10-fold less accurate than the T4 or native T7 DNA polymerases.

Although, the use of various newly introduced thermostable DNA polymerases with proofreading activities and lower misincorporation rates during synthesis may be an advantage to PCR users for direct cloning and sequencing of PCR products, PCR-based methods for mutagenesis, or detection of point mutations, the remaining concern is the degradation of primers in the PCR reaction mixtures by these enzymes. From a comparative study of the exonuclease activities and temperature profiles of Vent and $p f u$ DNA polymerases, it has been claimed that $p f u$ has a much lower primer degradation activity than the Vent DNA polymerase (E. Mathur, pers. comm.).

\section{DETECTION OF RELEASED GEMS IN THE ENVIRONMENT BY PCR}

There are many promising applications of GEMs in industry, agriculture, and medicine, but their use has been limited thus far because of a lack of sensitive methods for the monitoring and detection of GEMs after their release in the environment. Cultural methods and methods such as colony hybridization, which depend on the ability to recover and culture the organism from an environmental sample, lack sensitivity due to the limited efficiency of recovering bacteria from natural environments. Extraction of microbial DNA from the environmental sample, either directly or after recovery of microbial cells, followed by gene probe hybridization, though more sensitive than cultural methods, still lacks the level of sensitivity required to determine the ultimate fate of GEMs because of the limited relative numbers of target gene sequences that may be present in the sample. ${ }^{(33)}$

PCR amplification of the engineered genes from the released microorganisms to several millionfold can potentially increase the sensitivity of detection of released GEMs in the environment. The PCR method was first applied to monitor GEMs by Steffan and Atlas. (33) They detected by PCR amplification a portion of the $1.3-\mathrm{kb}$ repeat sequence from Pseudomonas cepacia AC1100, a herbicide $(2,4,5-\mathrm{T})$ degrading bacterium, after the organism was released in the soil. Their sensitivity of detection was 100 GEMs in 100 grams of sediment against a background of $10^{11}$ diverse nontarget microorganisms, at least $10^{3}$-fold higher than the sensitivity of nonamplified conventional dot-blot hybridization detection.

In another example, a $0.3-\mathrm{kb}$ unique DNA sequence from Pennisetum purpureum (napier grass) was cloned into pRC10, a derivative of 2,4dichlorophenoxyacetic acid-degrading plasmid, and transferred into Escherichia coli. ${ }^{(34)}$ This genetically altered microbe was then released into filtersterilized lake and sewage-water samples at a concentration of $10^{4}$ cells per milliliter. The microbe was detected by PCR at a sensitivity several-fold higher than the conventional plating technique, even after 10-14 days of in- cubation, using the unique cloned DNA sequence as a target.

These studies show that the PCR method can be used for monitoring released GEMs in an environment consisting of a complex habitat of diverse microorganisms, in which it may be tedious and time consuming to discriminate the GEMs from the indigenous microorganisms.

In another study, a single copy of the transposon Tn5 was transferred into the genomic DNA of Rhizobium leguminosarum, which was released into the soil. These GEMs were detected by "double" PCR amplification using the transposon $\operatorname{Tn} 5$ as target to a sensitivity of $1-10 \mathrm{cfu} / \mathrm{gram}$ of soil. ${ }^{(8)}$ Although it is adequate to use $\operatorname{Tn} 5$, which contains an antibiotic resistance gene as a model target for PCR detection, this may not be an appropriate marker for releasing GEMs into the environment because of Tn5's ability to be transferred into indigenous microorganisms, making them antibiotic resistant also. Detection of the indigenous Tn5 sequence by PCR may give false-positive results in such cases.

\section{DETECTION OF INDIGENOUS MICROORGANISMS IN THE ENVIRONMENT BY PCR \\ Detection of Degrading Microorganisms}

One of the potential ways to eliminate various pollutants and toxic wastes in the environment is efficient biodegradation and bioremediation by various indigenous microorganisms at the polluted sites. Sensitive detection of such degrading microorganisms in the polluted and toxic waste sites may be possible by using PCR. Although there might be variations in the genes of the same or different groups of microorganisms for the degradation of one or several types of pollutants, it may be possible to identify these microorganisms by detecting the conserved regions of these genes by PCR amplification.

One such study used the nucleotide sequence information of a chlorocatechol dioxygenase-degrading gene (tfdC) from Alcaligenes eutrophus JMP134 (pJP4); oligonucleotide primers were designed for the detection of various chloro-aromatic-degrading bacteria by PCR amplification. (35) PCR amplifi- 
cation using such oligonucleotide primers provides information quickly on the variations, similarities, and functional aspects of various pollutantdegrading genes present in closely or distantly related microorganisms in the environment. When such a polluted site is identified, it is important to investigate the possibility of the presence of various degrading microbes at that site. In many instances, conventional microbiological techniques do not detect all the pesticide-degrading indigenous microorganisms, as some of them may be in a viable but nonculturable condition.

In another study, specific detection of a herbicide (2,4-dichlorophenoxyacetic acid)-degrading bacteria was achieved by PCR amplification of a region of $t f d B$ gene from $\mathrm{pJP} 4$ and its derivative plasmid pRO103 (I. Pepper, pers. comm.). In this study, by using direct PCR amplified DNA analysis, it was possible to detect approximately $3000 \mathrm{cfu}$ or $15.6 \mathrm{pg}$ of plasmid DNA. The sensitivity of such detection was onefold higher when DNA-DNA hybridization was performed with an oligonucleotide probe internal to the amplified DNA. Using such oligonucleotide primers and PCR amplification, it is possible to detect the specific microorganisms carrying the degrading gene from a complex mixed microbial population in the environment.

\section{Identification of Microorganisms in Biofilms}

Formation of biofilms on various surfaces by microorganisms in the environment can be beneficial or detrimental. For example, microbial aggregation or attachment is required for various water treatments; on the other hand, extensive corrosion and biodeterioration can be caused due to the formation of such microbial biofilms. Characterization and ecology of microbial populations in biofilms has been hindered because the available determinative techniques require culture of microorganisms in selective media. These methods eliminate many of the important microbes from the biofilms since they survive only in a mixed culture and live on the cometabolism (the gratuitous metabolic transformation of a substance by a microorganism growing on another sub- stance). PCR amplification of specific targets makes it possible to identify a group of microbes in such a biofilm that may have been missed by the conventional techniques. To determine the feasibility of PCR, a sulfidogenic biofilm has been established in an anaerobic fixed-bed bioreactor. PCR amplification was performed for the detection of the population architecture of all the Gram-negative sulfatereducing bacteria using a region of the $16 \mathrm{~S}$ ribosomal $\mathrm{RNA}$ conserved in the resident sulfate reducing bacteria. ${ }^{(36)}$

\section{DETECTION OF INDICATOR MICROORGANISMS IN WATER}

The bacteriological safety of water supplies is tested by monitoring coliform bacteria whose presence in the water indicates potential human fecal contamination and the possibility of the presence of enteric pathogens. Coliform bacteria are traditionally detected by culturing on media such as MacConkey, m-Endo, eosin methylene blue, or brilliant-green-lactose-bile media.

The culture method for monitoring $E$. coli in environmental and potable waters has several problems associated with it. The conventional confirmative tests for the detection of $E$. coli, all of which require culturing of the organism, are time consuming. Moreover, they do not detect viable but nonculturable bacteria, which may occur due to chlorine injury during the process of water purification and treatment. Also, the cells may die between the time of collection and the test.

A colorimetric test, the Colilert test, for the detection of $E$. coli is based on the detection of $\beta$-D-glucuronidase enzyme produced by uidA gene. This method requires the culturing of bacteria. In addition, this method fails to detect $\beta$-D-glucuronidase-negative $E$. coli.

Bej et al. ${ }^{(18)}$ have developed a PCR gene probe-based method for the detection of coliform bacteria. Amplification of a portion of the lacZ gene detects $E$. coli and other coliform bacteria, including Shigella spp. Amplification of part of the lamB gene detects $E$. coli, Salmonella, and Shigella spp. In another study, Bej et al. ${ }^{(37)}$ developed a method for the detection of $E$. coli and Shigella spp. using four different regions of the uidA gene, which codes for the $\beta$-glucuronidase enzyme, and part of the uidR gene, which is the regulatory region of the uidA gene, as targets. Besides being less time consuming and having higher specificity and sensitivity, the most important advantage of this method over conventional and other commercially available methods is that it can detect the uidA-negative $E$. coli that do not show a positive signal with the conventional tests because they lack the $\beta$ glucuronidase enzyme. The sensitivity of the method is $1-10 \mathrm{fg}$ of genomic DNA and $1-5$ viable $E$. coli cells.

Similarly, Cleuziat and BaudouyRobert $^{(38)}$ have used a large region of the uid gene of $E$. coli as a target for PCR amplification and gene probe detection of E. coli and Shigella spp. This PCR gene probe-based method has the specificity and sensitivity required for monitoring coliforms as indicator organisms in environmental and potable waters.

A field evaluation of PCR detection of enteric pathogens and indicator microorganisms has been reported using uidA and lacZ as targets. (39) Although these targets for PCR amplification detection show great promise, the targets for specific detection of $E$. coli, Shigella spp., and Salmonella spp. are yet to be described.

\section{DETECTION OF WATER-BORNE MICROBIAL PATHOGENS BY PCR}

Apart from the detection and monitoring of indicator microorganisms for water quality assessment, it is also important to detect with high sensitivity and specificity various water-borne microbial pathogens.

\section{PCR Detection of Legionella}

Legionella spp. is a water-borne microbial pathogen and can cause Legionnaires' disease in humans via aerosol. Starnbach et al. ${ }^{(40)}$ reported the detection of Legionella pneumophila by amplification of a fragment of DNA of unknown function from Legionella using PCR. Their sensitivity of detection was equivalent to 35 colony forming units detected by viable plating. Mahbubani et al. ${ }^{(4)}$ have developed a method based upon PCR and gene probes for detecting Legionella in environmental water sources. All species 
of Legionella, including all 15 serogroups of $L$. pneumophila, were detected by PCR amplification of a 104-bp DNA sequence that codes for a region of $5 \mathrm{~S}$ rRNA followed by radiolabeled oligoprobe hybridization to an internal region of the amplified DNA. Strains of $L$. pneumophila (all serogroups) were specifically detected based upon amplification of a portion of the coding region of the macrophage infectivity potentiator (mip) gene. Pseudomonas spp. that exhibit antigenic cross-reactivity in serological detection methods did not produce positive signals in the PCR gene probe method using Southern blot analyses. Single-cell, single-gene Legionella detection was achieved with the PCR gene probe methods.

\section{PCR Detection of Giardia}

Another microbial pathogen, Giardia lamblia, causes defined waterborne diarrhea in the United States and in many other parts of the world. Diagnosis of $G$. lamblia from environmental samples is performed by concentrating 100 gallons of water followed by $\mathrm{mi}$ croscopic examination using fluoroscent dye. Using PCR amplification of different segments of the giardin gene of $G$. lamblia, it was possible to differentiate $G$. lamblia from $G$. muris. ${ }^{(42)}$ Also, a single Giardia cyst was detected by PCR amplification after separating the cyst by a micromanipulator. ${ }^{(43)} \mathrm{Al}$ though the specificity and sensitivity of the detection of Giardia shows great promise for rapid and reliable monitoring of this pathogen in water, application of this method for the detection of this pathogen in concentrates of 100 gallons of environmental water sample needs to be demonstrated.

\section{MULTIPLEX PCR AMPLIFICATION FOR ENVIRONMENTAL MONITORING OF MICROORGANISMS}

It is possible that environmental samples and drinking water may contain more than one type of microbial pathogen in addition to the indicator microorganism. Use of multiplex PCR for amplification and detection of more than one target in a single PCR reaction can be useful for monitoring multiple microbial pathogens in a single environmental or water sample. This method was first described by Chamberlain et al. ${ }^{(4)}$ for detecting hu- man genes.

A modification of this approach of simultaneous PCR amplification of multiple targets associated in different bacteria in the environmental samples has been demonstrated. ${ }^{(45)}$ Multiplex amplification of two different Legionella genes, one specific for Legionella pneumophila (mip) and the other for the genus Legionella (5S rRNA), was achieved by staggered addition of two different sets of primers at two different concentrations. ${ }^{(45)}$ This method can detect genus Legionella and $L$. pneumophila should they be present in one sample. Using the same target genes, mip and 5S rRNA, a multiplex PCR assay for genus Legionella and $L$. pneumophila was described. ${ }^{(46)}$ In this study, equal amplified products were achieved by adding equimolar quantities of each of the primers. This may be due to the fact that the two target sequences were closer in length than in the system developed and described previously. ${ }^{(1,+1,+5)}$

In a field study of water quality monitoring, simultaneous PCR amplification was performed using lacZ and uidA as targets. In this study, it was posssible to detect in one sample total coliform bacteria by amplification of the lacZ gene, the indicator microorganism E. coli, and a pathogen Shigella spp. by the amplification of the uidA gene. ${ }^{(36)}$ Also, in this study the lacZ PCR detection method gave results statistically equivalent to those of the conventional plate count and defined substrate methods accepted by the U.S. Environmental Protection Agency for water quality monitoring. The uidA PCR method was more sensitive than the 4-methylumbelliferyl- $\beta$-D-glucuronide-based defined substrate test for the specific detection of $E$. coli.

In another study multiplex amplification of five different targets in a single PCR reaction has been achieved for the detection of nonpneumophila Legionella spp., L. pneumophila, total coliforms, E. coli and Shigella spp., and total eubacterial species. (47)

It may be desirable in future studies to group certain microbial pathogens and indicators in the environmental samples and design the primers for specific targets. For example, one can group all the environmental and water-borne respiratory pathogens and PCR amplify all the specific target genes in a single reaction for their detection. When several GEMs are released together for the degradation of complex hazardous wastes and pollutants, they can be monitored together, possibly both qualitatively and quantitatively, in a single PCR reaction by amplifying a unique segment of the DNA of each of the GEMs, as well as by amplifying a common segment of all the GEMs that is not present in other eubacterial species.

\section{DETECTION OF VIABLE BUT NONCULTURABLE MICROORGANISMS IN THE ENVIRONMENT}

There are several reports on the existence of many microorganisms, including human pathogens, in the environment in a viable but nonculturable, i.e., dormant, stage. ${ }^{(48-50)}$ These microbial pathogens are shown to be potentially infectious when suitable conditions prevail. ${ }^{(48)}$ One obvious difficulty in elucidating this potential hazard is the inability to detect these viable but nonculturable cells in the environment because routine microbiological methods will not allow them to grow (on agar media) or will not distinguish them from the dead cells (by microscopic technique).

Recognizing that the terms "alive" and "viable" are subject to different definitions, the reasonably acceptable definition would be that the live cells are considered those capable of cell division, metabolism (respiration), or gene transcription (mRNA production). ${ }^{(49.50)}$ To detect those microbial cells that are in a viable but nonculturable state in the environment, it is desirable to target the mRNA rather than the DNA first for CDNA synthesis followed by PCR amplification. The potential problem of this approach is that most of the prokaryotic mRNAs have half-lives of only few minutes.

\section{PCR Detection of L. pneumophila}

Mahbubani et al. ${ }^{(51)}$ have shown that the mRNA of the mip gene of $L$. pneumophila can be stabilized simply by growing the cells for $10-15 \mathrm{~min}$ in the presence of chloramphenicol before harvesting. They have shown that the PCR amplification of the mip mRNA could be a potential means for the detection of metabolically active $L$. pneumophila cells. The use of chloram- 
phenicol for increasing the stability of bacterial mRNA is yet to be tested in other microorganisms.

Another perplexing issue that may create additional problems in such an approach is the efficiency of gene expression of these dormant microbial pathogens. It is possible that the transcriptional or regulatory systems of the target genes in these microbial pathogens are inhibited by various environmental factors and inhibitors when they are present in the natural environment. Therefore, in this situation the quantity of the target mRNA level may be so low that it may remain undetected even by a method as sophisticated as PCR. However, it has been shown by Bej et al. ${ }^{(52)}$ and Brauns et al. ${ }^{(53)}$ that targeting DNA for PCR amplification may be sufficient for the detection of culturable and nonculturable microbial pathogens. Both viable culturable and viable nonculturable cells of $L$. pneumophila, formed during exposure to hypochlorite, showed positive PCR amplification, whereas nonviable cells did not. Field verification of this approach for the detection of metabolically active (viable vs. dead) $L$. pneumophila from contaminated environmental samples is yet to be done. ${ }^{(52)}$

\section{PCR Detection of Vibrio vulnificus}

Besides L. pneumophila, another important marine water-borne microbial pathogen, Vibrio vulnificus, which can cause fatal infections in humans who ingest contaminated raw oysters, has been found to enter in a viable but nonculturable state during the colder months and resuscitate from the nonculturable state when a suitable environment prevails. ${ }^{(54,55)}$ Using PCR amplification of the hemolysin gene, Brauns et al. ${ }^{(53)}$ detected 72 pg of DNA from culturable and $31 \mathrm{ng}$ from nonculturable cells.

\section{Difficulties in Detection of Nonculturable Cells by PCR}

Although the decreased sensitivity of detection of nonculturable cells by PCR is not well understood at this time, several possible explanations have been described. ${ }^{(53)}$ Among these posibilities, the important criteria that may be of concern in applying PCR methodology for the detection of vi- able but nonculturable microorganisms are: (1) less DNA content per cell, (2) difficulty in breaking open the cell because of the change in the cell wall that may occur due to carbon or nitrogen starvation or changes in the environmental conditions, and (3) modification of the target gene due to genetic rearrangement. However, Brauns et al. ${ }^{(53)}$ did not attempt to use hemolysin mRNA as a target for PCR amplification from the nonculturable cells, a method that could have determined the exact nature of the cells (i.e., alive or dead), and the gene expression of the target.

A study by Mahbubani et al. ${ }^{(4)}$ has shown that mRNA-PCR alone is not sufficient to distinguish live Giardia cysts from dead ones, since cysts killed by heat treatment or monochloramination also give positive mRNA PCR amplification. Therefore, in this organism, if the giardin mRNA is used as a target for PCR amplification, it is necessary to include an mRNA induction step in the procedure to determine the viability of the cysts.

Since in the viable but nonculturable stage there may be changes in the structure as well as in gene expression in many microorganisms, a modified version of the PCR method may need to be developed for the detection of such microbial pathogens in the environment.

\section{Detection of Gene Expression in the Environment by PCR}

An important issue in environmental microbial molecular genetics is how various genes are regulated and expressed under various environmental conditions. One known fact is that some of the environmental microbial pathogens such as L. pneumophila and $V$. vulnificus alter their gene expression and remain in a dormant stage as nonculturable organisms in the environment. It has also been predicted that several biodegradative microorganisms may not express their degrading genes in the environment. As a result, one may not be sure whether the released GEMs or indigenous microorganisms are degrading the pollutants at a contaminated site. Using specific mRNA as a target for PCR amplification and developing a quantitative assay for such a method, it is possible to detect the level of mRNA production with high sensitivity in the environmental samples. A promising method for extraction of specific mRNA from soil seeded with naphthalene-degrading and mercury-resistant bacterial cells has been described. (9) This method can be completed within a few hours; approximately $17 \mu \mathrm{g}$ of total RNA per gram (wet weight) of soil containing $8 \times 10^{8}$ bacterial cells can be purified with a DNA-RNA hybridization detection sensitivity of $160 \mathrm{ng}$ of specific target mRNA. Although, this method has potential for studying in situ gene expression, the humic acid compounds may precipitate with samples containing high-cation-exchange capacity, e.g., some sediments, which will greatly reduce the total RNA recovery efficiency and sensitivity of detection. Application of PCR for detecting specific mRNA extracted from various environmental samples by this method has yet to be evaluated.

\section{DISCUSSION}

Although the application of PCR in the area of environmental microbiology has not progressed as much as applications in diagnostics, medicine, and molecular biology, several studies have shown great promise in solving various difficult problems. One of the most important problems in environmental microbiology is the detection and monitoring of released GEMs in the environment with high sensitivity. It has been shown that the application of the PCR method can detect 1-100 GEMs per gram of soil or sediment, which is a level of sensitivity several orders of magnitude higher than the conventional DNA-DNA hybridization method. One of the drawbacks of this approach is that PCR requires purified nucleic acid, which must be achieved from the environmental samples through several rigorous methodological steps.

The application of PCR technology to monitoring pathogens and indicator microorganisms has reached a stage where it is safe to say that this method can be used, with greater specificity and sensitivity, as an alternative to the conventional methods. The most important criterion in applying PCR technology in this area of environmental microbiology is the removal of in- 
hibitors and contaminants from the samples. Although several inhibitors from various environmental samples have been identified with possible removal procedures, unlimited numbers of such inhibitors may exist that have not yet been identified. For detection of microorganisms from soil and sediments, it has been found that the humic and fulvic acid compounds inhibit the polymerase activities and reduce the sensitivity of detection. Although, several procedures such as diluting the samples, ion-exchange chromatography, gel filtration chromatography, PVPP treatment, sucrose gradient purification, and so forth, have been used to remove humic and fulvic acids and other inhibitors from the samples, none of these methods seems to remove them totally. The application of PCR technology to various environmental samples for detection of pathogens and other microorganisms may be affected severely if a relatively universal method for removal of inhibitors from the environmental samples is not developed.

Quantitation of microbial populations by conventional methods has several drawbacks. Although there are several reports on the quantitation of PCR-amplified products that can give information about the starting number of cells, this approach needs to be developed for the quantitation of a microbial population in a given environment. This will permit microbial succession, competition, and community structure in an ecosystem to be studied in the environment, including microbes living in many extreme environments.

Another potential application of PCR methodology in the area of environmental microbiology is distinguishing the live cells from the dead ones in a given environmental sample. However, more research must be done before this approach can be applied to actual environmental samples.

Alteration of gene expression in many microbial pathogens and other pollutant-degrading microbes due to various environmental conditions is a growing concern to human health, and detection of specific mRNA in the environment by PCR will provide information on the in situ activity of these microorganisms. PCR shows promise for cloning genes from en- vironmentally important microorganisms, including those organisms that have not been cultured yet. In the near future, technological improvements and subsequent new development of the PCR method will solve many unanswered questions in the area of $\mathrm{mi}$ crobial ecology, microbial community structure, environmental health, and environmental analyses of molecular microbiology.

\section{ACKNOWLEDGMENT}

We are grateful to Daniel D. Jones for encouragement and help in preparing the manuscript.

\section{REFERENCES}

1. Mullis, K.B. and F.A. Faloona. 1987. Specific synthesis of DNA in vitro via a polymerase-catalyzed chain reaction. Methods Enzymol. 155: 335-351.

2. Saiki, R.K., S. Scarf, F.A. Faloona, K.B. Mullis, G.T. Horn, H.A. Erlich, and N. Arnheim. 1985. Enzymatic amplification of $\beta$-globin genomic sequences and restriction site analysis for diagnosis of sickle cell anemia. Science 230: 1350-1354.

3. Saiki, R.K., D.H. Gelfand, S. Stoffel, S.J. Scharf, R. Higuchi, G.T. Horn, K.B. Mullis, and H.A. Erlich. 1988. Primer-directed enzymatic amplification of DNA with a thermostable DNA polymerase. Science 239: $487-$ 494.

4. Bej, A.K., M.H. Mahbubani, and R.M. Atlas. 1991. Amplification of nucleic acids by polymerase chain reaction (PCR) and other methods and their applications. Crit. Rev. Biochem. Mol. Biol. (in press).

5. Steffan, R.J. and R.M. Atlas. 1991. Polymerase chain reaction: Applications in environmental microbiology. Anmu. Rev. Microbiol. 45: 137-161.

6. Steffan, R.J., J. Goksoyr, A.K. Bej, and R.M. Atlas. 1988. Recovery of DNA from soils and sediments. Appl. Environ. Microbiol. 54: 2908-2915.

7. Tsai, Y. and B.H. Olson. 1991. Rapid method for direct extraction of DNA from soil and sediments. Appl. Environ. Microbiol. 57: 1070-1074.

8. Pillai, S.D., K.L. Josephson, R.L. Bailey, C.P. Gerba, and I.L. Pepper. 1991. Rapid method for processing soil samples for polymerase chain reaction amplification of specific gene sequences. Appl. Environ.
Microbiol. 57: 2283-2286.

9. Tsai, Y., M.J. Park, and B.H. Olson. 1991. Rapid method for direct extraction of mRNA from seeded soils. Appl. Environ. Microbiol. 57: 765-768.

10. Sommerville, C.C., I.T. Knight, W.L. Straub, and R.R. Colwell. 1989. Simple, rapid method for direct isolation of nucleic acids from aquatic environments. Appl. Environ. Microbiol. 55: 548-554.

11. Day, P.J.R., I.S. Bevan, S.J. Gurney, L.S. Young, and M.R. Walker. 1990. Synthesis in vitro and application biotinylated DNA probes for human papilloma virus type 16 by utilizing the polymerase chain reaction. Biochem. J. 267: 119-123.

12. Paul, J.H., L. Cazares, and J. Thurmomd. 1990. Amplification of the rbcL gene from dissolved and particulate DNA from acquatic environments. Appl. Environ. Microbiol. 56: 1963-1966.

13. Weller, R. and D.M. Ward. 1989. Selective recovery of $16 \mathrm{~S}$ rRNA sequences from natural microbial communities in the form of cDNA. Appl. Environ. Microbiol. 55: 1818-1822.

14. Fuhrman, J.A., D.E. Comeau, A. Hagstrom, and A.M. Cham. 1988. Extraction from natural planktonic microorganisms of DNA suitable for molecular biological studies. Appl. Environ. Microbiol. 54: 1426-1429.

15. Lee, S. and J.A. Fuhrman. 1990. DNA hybridization to compare species compositions of natural bacterioplankton assemblages. Appl. Environ. Microbiol. 56: 739-746.

16. Zehr, J.P. and L.A. McReynold. 1989. Use of degenerate oligonucleotides for the amplification of the nifH gene from the marine cyanobacterium Trichodesmium thiebautii. Appl. Environ. Microbiol. 55: 2522-2526.

17. Bej, A.K., M.H. Mahbubani, J.L. DiCesare, and R.M. Atlas. 1991. PCRGene probe detection of microorganisms using filter-concentrated samples. Appl. Environ. Microbiol. (in press).

18. Bej, A.K., R.J. Steffan, J.L. DiCesare, L. Haff, and R.M. Atlas. 1990. Detection of coliform bacteria in water by polymerase chain reaction and gene probes. Appl. Environ. Microbiol. 56: 307-314.

19. Erlich, H.A., D. Gelfand, and J.J. 
Sninsky, 1991. Recent advances in the polymerase chain reaction. Science 252: 1643-1651.

20. Mullis, K.B. 1991. The polymerase chain reaction in an anemic mode: How to avoid cold oligodeoxyribonuclear fusion. PCR Methods Applic. 1: 1-4.

21. Orrego, C. 1990. Organizing a laboratory for PCR work. In $P C R$ protocols: A guide to methods and applications (ed. M.A. Innis, D.H. Gelfand. J.J. Sninsky, and T.J. White), pp. 447-454. Academic Press, San Diego.

22. Sarkar, G. and S.S. Sommer. 1990. More light on PCR contamination. Nature 347: 340-341.

23. Isaacs, S.T., J.W. Tessman, K.C. Metchette, J.E. Hearst, and D. Cimino. 1991. Post-PCR sterilization: Development and application to an HIV-1 diagnostic assay. Nucleic Acids Res. 19: 109-116.

24. Jinno, Y., K. Yoshiura, and N. Niikawa. 1990. Use of psoralen as extinguisher of contaminated DNA in PCR. Nucleic Acids Res. 18: 6739.

25. Longo, M.C., M.S. Berninger, and J.L. Hartley. 1990. Use of uracil DNA glycosylase to control carry-over contamination in polymerase chain reaction. Gene 93: 125-128.

26. Cariello, N.F., J.A. Swenberg, and T.R. Skopek. 1991. Fidelity of Thermococcus litoralis DNA polymerase (Vent) in PCR determined by denaturing gradient gel electrophoresis. Nucleic Acid. Res. 19: 4193-4198.

27. Ling, L.L., P. Keohavong, C. Dias, and W.G. Thilly. 1991. Optimization of the polymerase chain reaction with regard to fidelity: Modified T7, Taq, and Vent DNA polymerases. PCR Methods Applic. 1: 63-69.

28. Eckert, K.A. and T.A. Kunkel. 1990. High fidelity DNA synthesis by the Thermus aquaticus DNA polymerase. Nucleic Acids Res. 18: 3739-3744.

29. Eckert, K.A. and T.A. Kunkel. 1991. DNA polymerase fidelity and the polymerase chain reaction. $P C R$ Methods Applic. 1: 17-24.

30. Vent ${ }^{T M}$ DNA polymerase technical bulletin from New England Biolabs. 1990 and 1991.

31. Mathur, E.J., K.S. Lundberg, D.D. Shoemaker, K.B. Neilson, S.A. Mathur, B.R. Scott, and J.A. Sorge. 1991. Characterization of a thermostable DNA polymerase with high fidelity. Genome Sequencing Conference III. Rockville, MD.

32. Eckert, K.A. and T.A. Kunkel. 1991. The fidelity of DNA polymerases used in the PCR. In Polymerase chain reaction: A practical approach (ed. M.J. McPherson, P. Quirke, and G.R. Taylor), pp. 227-246. IRL Press at Oxford University Press, Oxford.

33. Steffan, R.J. and R.M. Atlas. 1988. DNA amplification to enhance the detection of genetically engineered microorganisms in environmental samples. Appl. Environ. Microbiol. 54: 2185-2191.

34. Chaudhry, G.R., G.A. Toranzos, and A.R. Bhatti. 1989. Novel method for monitoring genetically engineered microorganisms in the environment. Appl. Environ. Microbiol. 55: 1301-1304.

35. Greer, C.W., D. Beaumier, $H$. Bergeron, and P.C.K. Lau, personal communication.

36. Amann, R.1., J. Stromley, R. Devereux, R. Keryl, and D.A. Stahl, in prepara. tion.

37. Bej, A.K., J.L. DiCesare, L. Haff, and R.M. Atlas. 1991. Detection of Escherichia coli and Shigella spp. in water by using polymerase chain reaction (PCR) and gene probes for uid. Appl. Environ. Microbiol. 57: 1013-1017.

38. Cleuziat, P. and J. Baudouy-Robert. 1991. Specific detection of Escherichia coli and Shigella species using fragments of genes coding for betaglucuronidase. FEMS Microbiol. Lett. 72: 315-322.

39. Bej, A.K., S.C. McCarty, and R.M. Atlas. 1991. Detection of coliform bacteria and Escherichia coli by multiplex polymerase chain reaction: Comparison with defined substrate and plating methods for water quality monitoring. Appl. Environ. Microbiol. 57: 2429-2432.

40. Starnbach, M.`., S. Falkow, and L.S. Tompkins. 1990. Species specific detection of Legionella pneumophila in water by DNA amplification and hybridization. J. Clin. Microbiol. 27: 1257-1261.

41. Mahbubani, M.H., A.K. Bej, R. Miller, L. Haff, J. DiCesare, and R.M. Atlas. 1990. Detection of Legionella with polymerase chain reaction and gene probe methods. Mol. Cell. Probes 4: 175-187.

42. Mahbubani, M.H., A.K. Bej, M.H.
Perlin, F.W. Schaefer, W. Jakubowski, and R.M. Atlas. 1991. The differentiation of Giardia duodenalis from other Giardia spp. based on the polymerase chain reaction and gene probes. $J$. Clin. Microbiol. (in press).

43. Mahbubani, M.H., A.K. Bej, M.H. Perlin, F.W. Schaefer, W. Jakubowski, and R.M. Atlas, in preparation.

44. Chamberlain, J.S., R.A. Gibbs, J.E. Ranier, P.N. Nguyen, and Radolf. 1988. Deletion screening of the Duchenne muscular dystrophy locus via multiplex DNA amplification. Nucleic Acids Res. 16: 11141-11156.

45. Bej, A.K., M.H. Mahbubani, R. Miller, J.L. DiCesare, L. Haff, and R.M. Atlas. 1990. Multiplex PCR amplification and immobilized capture probes for detection of bacterial pathogens and indicators in water. Mol. Cell. Probes 4: $353-365$.

46. Picone, T., McCallum, and M. Zoccoli, personal communication.

47. Bej, A.K. and R.M. Atlas, personal communication.

48. Colwell, R.R., P.R. Brayton, D.J. Grimes, D.B. Roszak, S.A. Huq, and L.M. Palmer. 1985. Viable but nonculturable Vibrio cholerae and released pathogens in the environment: Implication for release genetically engineered microorganisms. BioTechnology 3: 817-820.

49. Hussong, D., R.R. Colwell, M.O. O'Brien, E. Weiss, A.D. Pearson, R.M. Eiener, and W.D. Burge. 1987. Viable Legionella pneumophila not detectable by culture on agar media. BioTechnology 5: 947-950.

50. Roszak, D.B. and R.R. Colwell. 1987. Survival strategies of bacteria in the natural environment. Microbiol. Rev. 51: $365-379$.

51. Mahbubani, M., A. Bej, J. DiCesare, R. Miller, L. Haff, and R.M. Atlas. 1991. Detection of bacterial mRNA using PCR. BioTechniques 10: 48-49.

52. Bej, A.K., M.H. Mahbubani, and R.M. Atlas. 1991. Detection of viable Legionella pneumophila in water by polymerase chain reaction and gene probe methods. Appl. Environ. Microbiol. 57: 597-600.

53. Brauns, L.A., M.C. Hudson, and J.D. Oliver. 1991. Use of the polymerase chain reaction in detection of culturable and nonculturable Vibrio vulnificans cells. Appl. Environ. Microbiol. 57: 2651-2655.

54. Linder, K. and J.D. Oliver. 1989. 
Membrane fatty acids and virulence changes in the viable but nonculturable state of Vibrio vulnificans. Appl. Environ. Microbiol. 55: 2837-2842.

55. Oliver, J.D., L. Nilsson, and S. Kjelleberg. 1991. Formation of nonculturable Vibrio vulnificus cells and its relationship to the starvation state. Appl. Environ. Microbiol. 57: 2640-2644. 


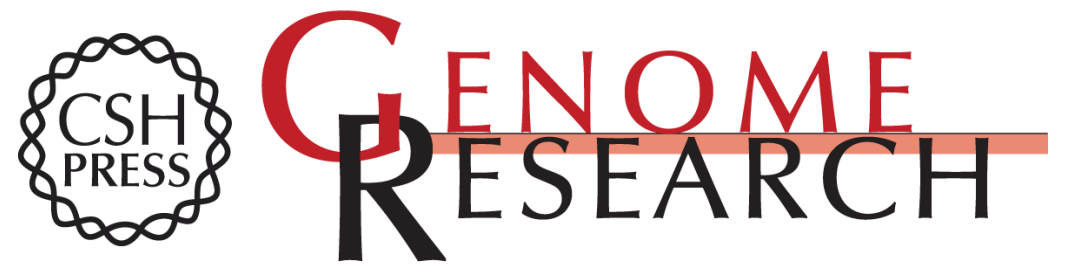

\section{Applications of the polymerase chain reaction in environmental microbiology.}

A K Bej and $\mathrm{M} \mathrm{H}$ Mahbubani

Genome Res. 1992 1: 151-159

Access the most recent version at doi:10.1101/gr.1.3.151

References This article cites 43 articles, 23 of which can be accessed free at:

http://genome.cshlp.org/content/1/3/151.full.html\#ref-list-1

\section{License}

Email Alerting Receive free email alerts when new articles cite this article - sign up in the box at the Service top right corner of the article or click here.

\section{Affordable, Accurate Sequencing.}

To subscribe to Genome Research go to: https://genome.cshlp.org/subscriptions 